\title{
Feeding Reduces Serum Concentration of Endogenous Bioactive (1-84), but Not Total Intact Parathyroid Hormone in Female Sprague-Dawley Rats
}

\author{
Jason R. DeGuire, Hope A. Weiler \\ School of Dietetics and Human Nutrition, McGill University, Montreal, Canada \\ Email: hope.weiler@mcgill.ca
}

Received December 29, 2012; revised January 13, 2013; accepted March 5, 2013

\begin{abstract}
Background: Interpretation of parathyroid hormone (PTH) measurements requires an understanding of its structural conformation. PTH reflects calcium intake and vitamin D status but is commonly measured in the fasted state using 2 nd generation assays, known to cross-react with PTH 7-84 fragments, which is not observed with 3rd generation assays. The objective was to determine if plasma PTH in the fed and non-fed state differ while controlling for diurnal rhythm and the generation of PTH assay. Methods: Blood was sampled, $2 \mathrm{~d}$ apart, from Sprague-Dawley rats (30 males and 30 females) in both fed and non-fed states at $20 \mathrm{wk}$ of age (weight: $470.2 \pm 23.2 \mathrm{~g}$ ) for measurement of ionized calcium (iCa), total intact (INT) and bioactive 1-84 (BIO) PTH. Differences between groups were tested using a GLIMMIX model with sex and feeding state as fixed effects and individual rats as a random effect. Results: Females had a lower $\mathrm{iCa}$ than males (F: $1.43 \pm 0.01$ vs M: $1.46 \pm 0.01 \mathrm{mmol} / \mathrm{L}, \mathrm{P}=0.03$ ). In males and females, there was no difference between fed and non-fed groups when PTH was assessed using the INT PTH assay (M Fed: $21.6 \pm 1.3$ vs M Non-fed: $22.6 \pm 2.3 \mathrm{pmol} / \mathrm{L}, \mathrm{P}=0.59$; F Fed: $19.3 \pm 1.5 \mathrm{vs} F$ Non-fed: $22.8 \pm 2.9 \mathrm{pmol} / \mathrm{L}, \mathrm{P}=0.39)$. However, in females only, PTH measured using the BIO PTH, was significantly lower in the fed group versus the non-fed (Fed: $8.4 \pm 0.8$ vs Non-fed: $16.7 \pm 3.4 \mathrm{pmol} / \mathrm{L}, \mathrm{P}=0.05)$. Conclusions: These results suggest that fasting elevates BIO PTH in females. Studies related to PTH should consider standardization of fast duration, sex differences, and preferentially use BIO PTH assays.
\end{abstract}

Keywords: Feeding; Sex; Parathyroid Hormone; Assay; Bioactive; Intact

\section{Introduction}

Parathyroid hormone $(\mathrm{PTH})$ is the primary determinant of the extent of bone remodeling activity in the skeleton. It regulates bone metabolism and mineralization in addition to maintaining calcium homeostasis in part by binding to the parathyroid hormone 1 receptor in bone and the kidney. Circulating PTH follows a diurnal and circadian rhythm [1-4] and is altered acutely by certain nutrients such as calcium [1,2] and chronically by conjugated linoleic acid (CLA) in healthy and polycystic kidney disease rats $[3,4]$. Thus when assessing PTH, both timing of sampling and standardized food intake patterns prior to sampling are required in trials designed to assess the physiological response of PTH to diet or supplements. Furthermore, PTH assays have evolved based on their clinical performance in differentiating bone diseases associated with renal failure [5].

\footnotetext{
${ }^{*}$ This research was supported by a collaborative research development grant from the Dairy Farmers of Canada and the Natural Sciences and Engineering Research Council of Canada.
}

First generation assays allowed for the description of circulating PTH immunoreactivity, however, these mainly reacted with PTH fragments without bioactivity. Second generation assays, known as intact PTH (INT), were initially thought to react only with the bioactive form of PTH (1-84) [5]. It was later discovered that these assays cross-reacted with the PTH fragments, notably PTH (7-84), which are suggested to antagonize the calcemic and bone resorptive effects of PTH (1-84). Third generation assays (BIO), with no cross-reactivity with the PTH fragments were thus developed to address the issue of the detection of fragments with biologically opposite effects [5]. Recently, in male and female cynomolgus monkeys, feeding reduced INT PTH suggesting that feeding state should be considered when interpreting PTH values [6]. The objective of this study was to confirm these results in another species and to assess possible differences in feeding state, sex and type of PTH assay used. It was hypothesized that: 1) feeding would reduce both INT and BIO PTH; 2) there would be no sex differences for both 
INT and BIO PTH; and 3) INT and BIO PTH assays will yield different values for PTH.

\section{Materials and Methods}

\subsection{Study Protocol and Diets}

All procedures and measurements were approved by the University of Manitoba Committee on Animal Care and conformed to Canadian Council on Animal Care guidelines [7]. This study was part of a larger study investigating the effect of CLA on bone and mineral metabolism [4]. Sprague-Dawley rats, (30 males and 30 females), were fed AIN-93G diets [8] from 3 to 20 wk of age with the exception of slightly higher fat content (84 $\mathrm{g} / \mathrm{kg}$ ) in all groups with the control group containing only soybean oil and the other dietary groups receiving $0.5 \%$ to $1 \%$ CLA. Animals were acclimatized to the housing conditions and housed (12 h light, $12 \mathrm{~h}$ dark cycle) in same-sex pairs, fed ad libitum and food disappearance monitored 3 times weekly over the study.

\subsection{Assessment of Growth, PTH and Ionized Calcium}

Body weight was measured weekly throughout the study using a weigh scale with a dynamic weighing program specifically for animal weighing (SB8001, MettlerToledo, Columbus, USA). Length was measured at wk 16 from nose to base of tail in the anesthetized state using isoflurane gas (AErrane ${ }^{\circledR}$, Baxter, Mississauga, Canada). At the wk 16 time-point, a blood sample of no more than $10 \%$ blood volume was taken from the tail vein, between 0800 and $1000 \mathrm{~h}$ to control for diurnal variation and separated to obtain serum for determination of PTH. Serum samples were stored at $-80^{\circ} \mathrm{C}$ until analysis. The fed state was a reflection of ad libitum intake during normal nocturnal feeding. Food was removed at $2000 \mathrm{~h}$ the night before the non-fed blood sampling 2 days after the fed blood sampling. Blood sampling of fed animals occurred first to ensure clearance of circulating PTH fragments. Moreover, a 2 day period between blood sampling was used to minimize stress to the animals and to allow for a complete feeding cycle in order to prevent any compensatory feeding after the fasting period. Blood was separated at $2000 \mathrm{~g}$ to obtain serum for determination of PTH using both second generation INT PTH and third generation BIO PTH using separate ELISA kits specific to rodent PTH (Alpco Diagnostics, Windham, USA). To assess intra- and inter-assay precision of both assays, the coefficient of variation (CV) was calculated from 20 triplicate determinations of two samples each performed in a single assay. For the BIO assay, intra-assay CV ranged from $2.5 \%-3.9 \%$ and inter-assay CV ranged from $7.8 \%-8.9 \%$. For the INT assay, in- tra-assay CV ranged from $2.1 \%-2.4 \%$ and inter assay $\mathrm{CV}$ ranged from $5.1 \%-6.0 \%$. Regarding serum ionized calcium (iCa), samples were measured within $4 \mathrm{~h}$ of collection using a Nova analyzer (Model 11, Nova Biomedical, Waltham, USA) with a $\mathrm{CV}<1.6 \%$.

\subsection{Statistical Analysis}

Data was analyzed using SAS statistical package software version 9.2.0 (SAS Institute Inc., Cary, USA). A GLIMMIX model included feeding state, sex, type of assay used and day of sampling combined with the individual animals included as a random factor. Diet was tested as a covariate, but did not significantly affect the results. This relatively new model was used to accommodate the Gaussian and non-Gaussian distribution and unequal variances of the data; all pair wise differences in diet means were tested using Tukey-Kramer approximation and a P-value of $\leq 0.05$ was accepted as significant. Data are presented as mean \pm SEM unless otherwise stated.

\section{Results}

At $20 \mathrm{wk}$ of age, females had $47.5 \%$ lower weight than males (F: $323.1 \pm 32.6$ vs M: $615.2 \pm 51.6 \mathrm{~g}, \mathrm{P}<0.0001$ ), $18.6 \%$ lower length (F: $21.5 \pm 0.5$ vs M: $26.4 \pm 0.8 \mathrm{~cm}, \mathrm{P}$ $<0.0001$ ), and $8.8 \%$ less food intake (F: $179.3 \pm 22.9$ vs M: $196.6 \pm 18.0 \mathrm{~g}, \mathrm{P}=0.003)$. Fed animals had significantly higher (1.4\%) iCa versus non-fed (fed: $1.45 \pm 0.01$ vs non-fed $1.43 \pm 0.01 \mathrm{mmol} / \mathrm{L}, \mathrm{P}=0.0002$ ). In males, $\mathrm{iCa}$ was $2.0 \%$ lower in the non-fed group versus fed (M non-fed: $1.43 \pm 0.01$ vs $\mathrm{M}$ fed: $1.46 \pm 0.01 \mathrm{mmol} / \mathrm{L}, \mathrm{P}=$ $0.003)$. A similar trend was observed in females $(1.4 \%$ lower), however, it did not reach significance ( $\mathrm{F}$ fed: $1.44 \pm 0.01$ vs $F$ non-fed: $1.42 \pm 0.01 \mathrm{mmol} / \mathrm{L}, \mathrm{P}=0.08$ ). There was a significant difference between sexes where females had a $2.1 \%$ lower iCa compared to males (F: $1.43 \pm 0.01$ vs $\mathrm{M}: 1.46 \pm 0.01 \mathrm{mmol} / \mathrm{L}, \mathrm{P}=0.03)$.

BIO PTH values were $48.6 \%$ lower $(\mathrm{P}<0.0001)$ than INT PTH. In females, there was no difference between fed and non-fed groups when PTH was assessed using the INT assay however, PTH measured using the BIO was lower in the fed group versus the non-fed. In males, there was no difference between fed and non-fed groups when measured with either BIO or INT assays (Figure 1).

\section{Discussion}

The results of the present study indicate that for the biological assessment of PTH, one should take into consideration sex, feeding state, and generation of assay (ELISA) used. The assays used in this study were from 


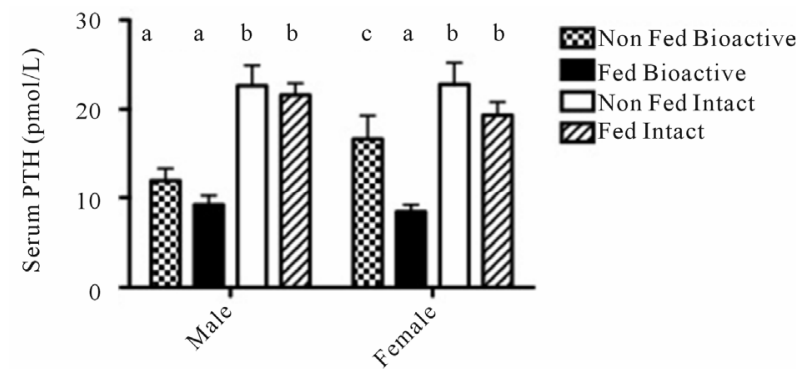

Figure 1. Effect of feeding on endogenous serum PTH concentration assessed using INT and BIO PTH assays in male and female rats. Differences detected using GLIMMIX model with post hoc testing using Tukey-Kramer approximation. Different letters indicate significant differences $(P<$ 0.05). Values are mean $\pm S E M ; n=30$ per sex.

the same manufacturer and were similar except for the horseradish peroxidase (HRP) conjugated detection antibody. The detection antibody in the INT assay binds to epitopes within the 13-34 amino acid region of the rat PTH molecule while the detection antibody in the BIO PTH assay binds to an initial amino terminal epitope of amino acids 1-3. Generally, the second-generation INT PTH assay reacts with both the PTH (1-84) and the shorter PTH fragments notably PTH (7-84), which, in a group of renal transplant patients, was reported to account for $44.1 \%$ of total plasma PTH [9].

Evidence suggests that PTH (7-84) fragments can lead to skeletal resistance to $\mathrm{PTH}$ and inhibit bone resorption and thus display an antagonistic action to PTH (1-84) $[9,10]$. Moreover, PTH (7-84) fragments have a half-life of $\sim 10$ minutes versus $\sim 4$ minutes for PTH (1-84) [11]. This could explain in part the higher PTH values measured by the INT PTH assay compared to the BIO PTH assay could reflect the sum of agonist and slow degrading antagonist fragments of PTH. These results are in agreement with Inaba et al. where the mean concentrations measured by the BIO PTH and INT PTH assays in healthy Japanese men and women were $62 \%$ higher in the INT assay, indicating that the PTH fragments account for $\sim 40 \%$ of circulating PTH immunoreactivity [12]. Thus, the results obtained with the second-generation INT assay may not accurately reflect parathyroid function or serum PTH concentration.

Nutritional intake and extended fasting periods (33 to 96 hours) can modulate the circadian rhythm of PTH [13, 14]. Additionally, plasma phosphate $\left(\mathrm{PO}_{4}\right)$ and $\mathrm{iCa}$ are known to be correlated with PTH [14-19], which emphasizes the importance of meal times, type of food ingested and the resulting flux of $\mathrm{PO}_{4}$ and $\mathrm{iCa}$ on $\mathrm{PTH}$. Serum $\mathrm{iCa}$, $\mathrm{PO}_{4}$ and $1,25(\mathrm{OH})_{2} \mathrm{D}_{3}$ are known to regulate serum $\mathrm{PTH}$, and in turn are regulated by changes in PTH [20,21]. An increase in $\mathrm{iCa}$ mediates a decrease in PTH secretion within seconds of being detected by calcium receptors in the parathyroid gland and this is accompanied by the breakdown of circulating PTH over the following hours [22]. $\mathrm{PO}_{4}$ independently increases $\mathrm{PTH}$ synthesis and secretion via a post-transcriptional mechanism occurring over a span of hours $[23,24]$, while $1,25(\mathrm{OH})_{2} \mathrm{D}_{3}$ decreases PTH via inhibition of PTH gene expression [25]. This study has demonstrated that being in a non-fed state for 8 to $10 \mathrm{~h}$ is sufficient to decrease $\mathrm{iCa}$, whereas the increase in PTH values were true for the BIO PTH assay only in females. It is possible that the already lower values for BIO PTH in some of the dietary groups of males but not females from the original study [4], precluded detection of differences in INT and BIO PTH between feeding states in males. Nonetheless, BIO PTH values for animals in the control diet were not different between feeding states (Fed 9.1 \pm 1.7 vs non-fed $9.8 \pm 2.3 \mathrm{pmol} / \mathrm{L}$, $\mathrm{P}=0.81)$; the same was true for INT PTH (Fed $22.1 \pm$ 2.3 vs non-fed $21.7 \pm 4.6 \mathrm{pmol} / \mathrm{L}, \mathrm{P}=0.97)$. In addition the iCa values for males were higher than females whereas BIO PTH was lower.

Overall our work contrasts that of Ruh et al. who found that in male and female monkeys, withdrawing food increases INT PTH [6]. The animals' food was removed for 7 hours and collected the blood samples in the late afternoon, which would also reflect circadian rhythm near the end of the expected feeding period. One of the reasons for the discrepancy might relate to the use of isoflurane anesthesia in rats, which is known to decrease $\mathrm{iCa}$ and increase INT PTH after induction of anesthesia and peaking after 30 minutes of exposure [26]. However, sampling in the rats was rapid within 10 to $15 \mathrm{~min}$ total. In summary, the present study suggests that the INT assay could mask the changes in PTH seen with sex and feeding states, at least in rats.

The assessment of PTH is difficult due to its complex metabolic and structural properties. Mallette first proposed that PTH could be considered as a "polyhormone" based on the multiple biological actions of single peptide regions of the PTH molecule [27]. This theory continues to be verified with ongoing discoveries of different forms of circulating PTH [28-30]. This reinforces the importance of careful selection of PTH assays depending on the purpose of the study. As demonstrated in this study, 2nd generation assays yield higher values than 3rd generation assays. Also, they appear to be unable to differentiate differences incurred based on sex although further PTH analyses using assays from different manufacturers is warranted to confirm these results. Future studies related to PTH should consider standardization of fast duration, sex effects, and measure BIO PTH.

\section{Acknowledgements}

The work was conducted at the University of Manitoba 
facilities and the associated Manitoba Institute of Child Health. The authors acknowledge the assistance with feeding and some sample collection and measurement by S. Fitzpatrick, M. Kaur, and R. Mollard and A. Dick. The authors have no conflict of interest.

\section{REFERENCES}

[1] T. Fujita, S. Ohgitani and Y. Fujii, "Overnight Suppression of Parathyroid Hormone and Bone Resorption Markers by Active Absorbable Algae Calcium. A Double-Blind Crossover Study," Calcified Tissue International, Vol. 60, No. 6, 1997, pp. 506-512. doi:10.1007/s002239900272

[2] W. R. McKane, S. Khosla, K. S. Egan, S. P. Robins, M. F. Burritt and B. L. Riggs, "Role of Calcium Intake in Modulating Age-Related Increases in Parathyroid Function and Bone Resorption," The Journal of Clinical Endocrinology and Metabolism, Vol. 81, No. 5, 1996, pp. 1699-1703. doi:10.1210/jc.81.5.1699

[3] H. A. Weiler, S. Austin, S. Fitzpatrick-Wong, E. Nitschmann, N. Bankovic-Calic, R. Mollard, H. Aukema and M. Ogborn, "Conjugated Linoleic Acid Reduces Parathyroid Hormone in Health and in Polycystic Kidney Disease in Rats," American Journal of Clinical Nutrition, Vol. 79, No. S6, 2004, pp. S1186-S1189.

[4] H. A. Weiler, S. Fitzpatrick and S. C. Fitzpatrick-Wong, "Dietary Conjugated Linoleic Acid in the cis-9, trans-11 Isoform Reduces Parathyroid Hormone in Male, but Not Female Rats," Journal Nutritional Biochemistry, Vol. 19, No. 11, 2008, pp. 762-769. doi:10.1016/j.jnutbio.2007.09.010

[5] P. Gao and P. D'Amour, "Evolution of the Parathyroid Hormone (PTH) Assay-Importance of Circulating PTH Immunoheterogeneity and of Its Regulation," Clinical Laboratory, Vol. 51, No. 1-2, 2005, pp. 21-29.

[6] C. Ruh, N. Doyle, P. Oldfield, P. Bednarek and S. Y. Smith, "Effects of Fasting on Endogenous Parathyroid Hormone (PTH) Levels in Cynomolgus Monkeys," Journal of Bone and Mineral Research, Vol. 25, No. S1, 2010, pp. S363-S502.

[7] Canadian Council on Animal Care, "Guide to the Care and Use of Experimental Animals," Bradda Printing Services Inc., Ottawa, 1993.

[8] P. G. Reeves, "Components of the AIN-93 Diets as Improvements in the AIN-76A Diet," Journal of Nutrition, Vol. 127, No. S5, 1997, pp. S838-S841.

[9] E. Slatopolsky, J. Finch, P. Clay, D. Martin, G. Sicard, G. Singer, P. Gao, T. Cantor and A. Dusso, "A Novel Mechanism for Skeletal Resistance in Uremia," Kidney International, Vol. 58, No. 2, 2000, pp. 753-761.

[10] P. Divieti, M. R. John, H. Juppner and F. R. Bringhurst, "Human PTH-(7-84) Inhibits Bone Resorption in Vitro via Actions Independent of the Type 1 PTH/PTHrP Receptor," Endocrinology, Vol. 143, No. 1, 2002, pp. 171176. doi:10.1210/en.143.1.171

[11] H. Yamashita, P. Gao, T. Cantor, T. Futata, T. Murakami, S. Uchino, S. Watanabe, H. Kawamoto, M. Fukagawa and S. Noguchi, "Large Carboxy-Terminal Parathyroid Hormone (PTH) Fragment with a Relatively Longer HalfLife than 1-84 PTH is Secreted, Directly From the Parathyroid Gland in Humans," European Journal of Endocrinology, Vol. 149, No. 4, 2003, pp. 301-306. doi:10.1530/eje.0.1490301

[12] M. Inaba, K. Nakatsuka, Y. Imanishi, M. Watanabe, Y. Mamiya, E. Ishimura and Y. Nishizawa, "Technical and Clinical Characterization of the Bio-PTH (1-84) Immunochemiluminometric Assay and Comparison with a Second-Generation Assay for Parathyroid Hormone," Clinical Chemistry, Vol. 50, No. 2, 2004, pp. 385-390. doi:10.1373/clinchem.2003.026831

[13] A. Schlemmer and C. Hassager, "Acute Fasting Diminishes the Circadian Rhythm of Biochemical Markers of Bone Resorption," European Journal of Endocrinology, Vol. 140, No. 4, 1999, pp. 332-337. doi:10.1530/eje.0.1400332

[14] W. D. Fraser, F. C. Logue, J. P. Christie, D. A. Cameron, D. S. Oreilly and G. H. Beastall, "Alteration of the Circadian-Rhythm of Intact Parathyroid-Hormone Following a 96-Hour Fast," Clinical Endocrinology, Vol. 40, No. 4, 1994, pp. 523-528.

[15] M. S. Calvo, R. Kumar and H. Heath, "Elevated Secretion and Action of Serum Parathyroid-Hormone in YoungAdults Consuming High Phosphorus, Low Calcium Diets Assembled from Common Foods," Journal of Clinical Endocrinology \& Metabolism, Vol. 66, No. 4, 1988, pp. 823-829. doi:10.1210/jcem-66-4-823

[16] W. D. Fraser, F. C. Logue, J. P. Christie, S. J. Gallacher, D. Cameron, D. S. J. O'Reilly, G. H. Beastall and I. T. Boyle, "Alteration of the Circadian Rhythm of Intact Parathyroid Hormone and Serum Phosphate in Women with Established Postmenopausal Osteoporosis," Osteoporosis International, Vol. 8, No. 2, 1998, pp. 121-126. doi:10.1007/BF02672507

[17] F. C. Logue, W. D. Fraser, D. S. Oreilly and G. H. Beastall, "The Circadian-Rhythm of Intact Parathyroid-Hormone (1-84) and Nephrogenous Cyclic Adenosine-Monophosphate in Normal Men," Journal of Endocrinology, Vol. 121, No. 1, 1989, pp. R1-R3. doi:10.1677/joe.0.121R001

[18] M. E. Markowitz, S. Arnaud, J. F. Rosen, M. Thorpy and S. Laximinarayan, "Temporal Interrelationships between the Circadian-Rhythms of Serum Parathyroid-Hormone and Calcium Concentrations," Journal of Clinical Endocrinology \& Metabolism, Vol. 67, No. 5, 1988, pp. 10681073. doi:10.1210/jcem-67-5-1068

[19] M. S. Calvo, R. Kumar and H. Heath, "Persistently Elevated Parathyroid-Hormone Secretion and Action in Young-Women after 4 Weeks of Ingesting High Phosphorus, Low Calcium Diets," Journal of Clinical Endocrinology \& Metabolism, Vol. 70, No. 5, 1990, pp. 13341340. doi:10.1210/jcem-70-5-1334

[20] E. Slatopolsky, A. Brown and A. Dusso, "Pathogenesis of Secondary Hyperparathyroidism," Kidney International, Vol. 73, 1999, pp. S14-S19. doi:10.1046/j.1523-1755.1999.07304.x

[21] E. Slatopolsky and J. A. Delmez, "Pathogenesis of Secondary Hyperparathyroidism," Nephrology Dialysis Trans- 
plantation, Vol. 11, 1996, pp. 130-135. doi:10.1093/ndt/11.supp3.130

[22] E. M. Brown, M. Pollak, C. E. Seidman, J. G. Seidman, D. Riccardi and S. C. Hebert, "Seminars in Medicine of the Beth-Israel-Hospital, Boston-Calcium-Ion-Sensing CellSurface Receptors," New England Journal of Medicine, Vol. 333, No. 4, 1995, pp. 234-240. doi:10.1056/NEJM199507273330407

[23] E. Reiss, J. M. Canterbury, M. A. Bercovitz and E. L. Kaplan, "Role of Phosphate in Secretion of Parathyroid Hormone in Man," Journal of Clinical Investigation, Vol. 49, No. 11, 1970, pp. 2146-2149. doi:10.1172/JCI106432

[24] E. Slatopolsky, A. Dusso and A. J. Brown, "The Role of Phosphorus in the Development of Secondary Hyperparathyroidism and Parathyroid Cell Proliferation in Chronic Renal Failure," American Journal of the Medical Sciences, Vol. 317, No. 6, 1999, pp. 370-376. doi:10.1097/00000441-199906000-00004

[25] T. Navehmany, M. M. Friedlaender, H. Mayer and J. Silver, "Calcium Regulates Parathyroid-Hormone Messenger Ribonucleic-Acid (Messenger-Rna), but Not Calcitonin Messenger-Rna in Vivo in the Rat-Dominant Role of 1,25-Dihydroxyvitamin-D," Endocrinology, Vol. 125, No. 1, 1989, pp. 275-280. doi:10.1210/endo-125-1-275

[26] C. E. Hotchkiss, R. Brommage, M. Du and C. P. Jerome, "The Anesthetic Isoflurane Decreases Ionized Calcium and Increases Parathyroid Hormone and Osteocalcin in Cynomolgus Monkeys,” Bone, Vol. 23, No. 5, 1998, pp. 479-484. doi:10.1016/S8756-3282(98)00124-0

[27] L. E. Mallette, "The Parathyroid Polyhormones-New Concepts in the Spectrum of Peptide-Hormone Action," Endocrine Reviews, Vol. 12, No. 2, 1991, pp. 110-117. doi:10.1210/edrv-12-2-110

[28] P. D'amour, J. H. Brossard, A. Rakel, L. Rousseau, C. Albert and T. Cantor, "Evidence that the Amino-Terminal Composition of Non-(1-84) Parathyroid Hormone Fragments Starts before Position 19," Clinical Chemistry, Vol. 51, No. 1, 2005, pp. 169-176. doi:10.1373/clinchem.2004.040485

[29] P. D'amour, J. H. Brossard, L. Rousseau, L. NguyenYamamoto, E. Nassif, C. Lazure, D. Gauthier, J. R. Lavigne and R. J. Zahradnik, "Structure of Non-(1-84) PTH Fragments Secreted by Parathyroid Glands in Primary and Secondary Hyperparathyroidism," Kidney International, Vol. 68, No. 3, 2005, pp. 998-1007. doi:10.1111/j.1523-1755.2005.00493.x

[30] A. Rakel, J. H. Brossard, J. V. Patenaude, C. Albert, E. Nassif, T. Cantor, L. Rousseau and P. D'Amour, "Overproduction of an Amino-Terminal Form of PTH Distinct from Human PTH(1-84) in a Case of Severe Primary Hyperparathyroidism: Influence of Medical Treatment and Surgery," Clinical Endocrinology, Vol. 62, No. 6, 2005, pp. 721-727. 